\title{
No Longer Ariel: Leaving the Archetypes of Children's Literature Behind and Learning to be My Own Strong Female Character
}

\author{
Rachel Sargeant, Simon Fraser University
}

If you ask my father, the earliest record of me loving books was when I was two or three years old, raptly listening to him read me Disney faerie ${ }^{1}$ tales and doing all the voices. If you ask my mother, it was when I was three or four and hearing me read my Little Mermaid picture book out loud over the baby monitor. While I have no recollection of those moments, I vividly remember being slightly older, maybe five or six, sitting in the front section of the grocery cart holding a Berenstain Bears book, cold from being in the freezer aisle while my mother shopped for milk and eggs.

Growing up, I was encouraged to read anything and everything, and so I consumed a steady diet of faerie tales, dinosaur encyclopedias, and Little Golden Books. My favourites were The Little Mermaid, because Ariel was the only Disney princess with red hair; The Unicorn's Secret: Moonsilver, after I started horseback riding at age six; and the Magic Tree House series. It was fantastical books like these that I first remember deeply connecting with. I loved learning the details of worlds not my own, and, in my child mind, dinosaurs were exactly like fantasy creatures, except they were real. What else in my books was real? Genres like portal fantasy and magic realism make you believe it's plausible that maybe, just maybe, magical things could happen to you, too. I wanted stories that had adventure, and the fantasy girl-marketed books that had unicorns and mermaids always had a brave female protagonist. Growing up so closely with books had the side effect of me basing my personality on protagonists I liked, which both hindered my ability to relate with the outside world but also helped me realize I didn't just have to read about brave girls - but could become one.

${ }^{1}$ I choose this spelling deliberately, to honour Celtic and other ancient traditions.

ENGL487W - Summer 2021 
I was an awkward child, and starting school only pushed me further toward individual activities, such as reading. I got overwhelmed much faster than regular Kindergarteners, wasn't good at making friends, and didn't understand how to deal with failure, which at that age that meant not being able to colour within the lines. Elementary school also did not treat me well, as intense bullying made it so I only attended half the time. I would immediately turn to books when I got home, using fantasy as both a calming method and escape. I used to spend hours at the local library, gathering stacks almost as tall as I was, with O.R. Melling's The Golden Book of Faerie, Liz Kessler's Emily Windsnap series, and Shelley Peterson's Sundancer on a nearly permanent loan.

Child protagonists are usually unusual, be they a half-mermaid, have the ability to portal into other worlds, or end up fulfilling prophecies. Beginning to read chapter books at a time when the majority of female protagonists were made "relatable" by descriptions of blonde hair and plain features, giving a character red hair was authorial shorthand to show their protagonist was exciting and special. Being one of two redheads in my elementary school and feeling the typical childlike sense of being different, I clung to characters like Ari from The Road to Balinor, Ginny from the Harry Potter series, and Amber from The Prophecy of the Stones, living vicariously through them. I liked reading about girls who were the opposite of me and my life - maybe they didn't have friends either, but they were brave and outspoken, throwing themselves into danger for the sake of others, gaining experiences I would never have. They were who I wanted to become, someone who made magical friends and went on adventures, persevering in fantasy worlds where they were important and celebrated for being different.

High school was when I really began exploring books, due to a combination of being an outsider and the sharp rise in popularity of the Young Adult genre. I had a book (or two) in my backpack at all times, sat on the floor outside my locker to read at lunch, and got in trouble multiple times from one snippy English teacher who wouldn't let me read in class after I had finished my work. Growing up during the boom of Middle Grade and Young Adult books both helped and hindered my perceptions of myself, particularly when it came to my sense of superiority from being not like other girls. At this time, my favourites included Lili St. Crow's Strange Angels series, the Mortal Instruments series by Cassandra Clare, Daughter of Smoke and Bone by Laini Taylor, and Tithe by Holly Black, all main characters who didn't fully embody traditional femininity and put higher value on

ENGL487W - Summer 2021 
learning to fight or create art, rather than on physical appearance. They were weird like me, yet they got the guy. They were different from their peers, yet they somehow ended up saving the world. I subconsciously attached to them in a way that went beyond relatability, and, in doing so, I changed myself so that I reflected their personalities. I felt more confident in myself because of these quirky characteristics, but it led to a rude awakening when I realized reading a lot didn't make me any smarter or better than other students. That being said, being exposed to characters who expressed various attitudes and ideas of strength at the volume and rate at which I was consuming them opened up my ideas of what being a strong protagonist was, and I credit a lot of my beliefs on strength and morals to what I read back then.

Having books be a central part of my life for over two decades, I've watched the ideals and biases of children's literature grow alongside my own understanding of what it means to read critically. Along with the expansion of dispositions of female leads, the bookish community is now more often holding people accountable for poor depictions of marginalized groups, starting new discussions on age-appropriate topics, and actively challenging accessibility. The influence children's literature had on me was positive in the way that it showed me what I could become, but also held me back, because it reinforced stereotypes and kept me from seeking certain relationships. My coping mechanisms were unhealthy because I put too much effort into escaping, and I had to un-learn a few quirks from these early-2000s types of protagonists, like realizing it was good to have female friends and to stop having crushes on people who treated you poorly. I have a healthier outlook on fantasy protagonists in my twenties than I did as a child, but I would not describe my enthusiasm for books as any less - if anything, it grew thicker roots when I worked at the bookstore, continues to grow each day I am a part of the book blogger community, and is what pushes me to work with writers to question the new media that has evolved from those earlier days of children's publishing. Having people like this in my life allows me to explore stories without becoming them, and talking with someone who understands your enthusiasm is its own kind of magic. I am forever grateful that these other worlds were accessible to me when I needed them most to escape, but also that they showed me my potential to become the protagonist of my own story. I've given Ariel a voice, but this time, it's my own.

ENGL487W - Summer 2021 
(c) $(1) \Theta$ This work is licensed under a Creative Commons Attribution-
NonCommercial-NoDerivatives 4.0 International License.

(C) Rachel Sargeant, 2021

ENGL487W - Summer 2021 